\title{
UNA OREJA EN EL PISO
}

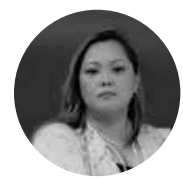

\section{MIDORI IKEDA}

- Profesora de Gerencia y Desarrollo de Producto

Dirección de Administración y Marketing

Facultad de Negocios, UPC

Hace un tiempo tuve la suerte de conversar con Orlando Olivieri y con Juan Ochoa, dos caballeros con gran experiencia y sabiduría en temas de marketing. Estuvimos discutiendo sobre un caso peruano de éxito, y fue en ese momento que escuché lo siguiente: "Un buen 'marketero' debe estar siempre con una oreja en el piso". Es decir, que no solo debe estar pendiente de sus actividades diarias, sino también de lo que sucede en el entorno. Sin embargo, actualmente no es suficiente oír y ver lo que sucede en el entorno. Se requiere, además, de una gran capacidad de análisis para adelantarse a la competencia en el desarrollo de productos y servicios que satisfagan las necesidades del consumidor.

Alcanzar esta capacidad de análisis no es fácil, considerando la enorme cantidad de información a la que estamos expuestos y a la cual podemos acceder. El desafío no es procesar la información, pues el desarrollo de la tecnología ha permitido la existencia de aplicaciones y programas que realizan esta tarea de procesamiento rápida y eficientemente: el reto es, más bien, analizar e interpretar dicha información para tomar decisiones acertadas.

En el pasado, el consumidor tenía mucho menos para elegir; se adquiría, digamos, lo que el mercado daba. Actualmente, existe una mayor cantidad de consumidores con más capacidad de gasto; $\mathrm{y}$, además, un mayor número de empresas. El mercado es mucho más complejo. Los consumidores tienen necesidades que quieren cubrir a través de la experiencia personalizada, factibles de satisfacer con la adquisición de tal o cual producto.

Para ello, existe una mayor disponibilidad de información para tomar las debidas decisiones, y las empresas usan esta información para identificar las necesidades del consumidor, de modo que puedan ofertar el producto correcto.

La interrogante que nos hacemos aquí, entonces, es cómo "escuchar" cuando hay tanta información y ruido. Una forma interesante es seguir el "viaje del consumidor".
El customer journey procura mapear las necesidades y los deseos del individuo a través del seguimiento que se le hace en el proceso de toma de decisiones y en su relacionamiento con la empresa. La herramienta será útil, pero solo si nos permite analizar las emociones de la persona: "La empatía no solo se trata de caminar con los zapatos de otro: primero tienes que quitarte los tuyos"1.

Para Daniel Goleman, uno de los componentes de la inteligencia emocional es la empatía, y la define como como el tener conciencia de los sentimientos, preocupaciones y necesidades que están presentes en los demás.

Puede parecer sencillo, pero ser empático implica saber cuándo escuchar, hablar o aconsejar; cómo se tiene que hablar; en qué tono se debe uno dirigir a la otra persona, sin juzgarla; etcétera.

Ahora, imaginemos trasladar todo esto al plano virtual. Procuremos, entonces, observar cómo manejan la comunicación los expertos modernos, los llamados social influencers.

Los social influencers son individuos que están especializados en un tema, se diversifican y crecen con los grupos, pero, sobre todo, informan y guían a los consumidores en sus decisiones. ¿Por qué son tan importantes y tienen seguidores? Podemos responder a esta interrogante observando a nuestro alrededor: cada vez que revisamos nuestra cuenta de correo, escuchamos radio, vemos televisión o salimos de casa recibimos gran cantidad de información, lo cual puede llegar a aturdirnos fácilmente. Nuestra mente hará una selección y se enfocará en almacenar lo que nos interesa. Ahora, el problema radica en determinar qué información es realmente cierta y valiosa para nosotros. Es en ese momento de incertidumbre cuando buscamos la opinión de alguien en quien confiamos, factor importante hoy en día para tomar decisiones. Desde la perspectiva comercial, la opinión positiva de varios influencers puede hacer que un negocio prospere o fracase desde su lanzamiento.

1. Frase atribuida a Scott Cook, CEO de Intuit, empresa de desarrollo de software. 
Un caso de éxito es el de Los Sanguchones de Kike ${ }^{3}$. Kike comenzó ofreciendo sándwiches con nombres atractivos para un segmento juvenil: La Jugadora, Megamutante Rompemandíbula, CSM, entre otros, y su única promoción son los carteles y el fanpage de su negocio; no obstante, todos los días tiene comensales haciendo fila para que les tomen la orden. La primera vez que fui, un sábado demoré 45 minutos en realizar mi pedido, y luego esperé entre media hora y 45 minutos a que lo prepararan y me lo sirvieran, en un local abarrotado al que seguían llegando más comensales.

¿Cuál es la razón de su éxito? ¿Por qué acuden tantos jóvenes? La respuesta la encontré en YouTube, en los videos de promoción, que no los hizo Kike: fueron grabados y subidos por varios influencers (youtubers, vblogers), como Kevo, Johan o Andy. Estos tres influencers tienen aproximadamente 353 000, 708000 y más de un millón de vistas, respectivamente. Imaginémonos aquí a un grupo de jóvenes viendo, comentando estas publicaciones, y poniéndose de acuerdo para pedir la Ultra-Mega-Kike, producto que se solicita con tres días de anticipación y que pesa seis kilogramos.

La conexión empática que se requiere con los consumidores va más allá de leer comentarios, papers o informes de investigación de mercado. La necesidad de "sumergirse y nadar" en la misma corriente demanda que estemos incluso más alertas, analizando al consumidor en la red y siguiendo a los influencers; es decir, con la oreja en la web.

¿Nuevos retos? ¡Vamos por más con la corriente! 